\title{
Retrospective Evaluation of the Outcomes in the Patients with Chiari's Malformation Undergoing Surgical Treatment
}

\author{
${ }^{1}$ Ismail KAYA*, ${ }^{2}$ İlker Deniz Cingöz, ${ }^{3}$ Nurullah Yüceer \\ ${ }^{1,2}$ Kutahya Health Science University, Medical Faculty, Department of Neurosurgery, Kutahya/TURKEY \\ ${ }^{3}$ Katip Çelebi University, Medical Faculty, Department of Neurosurgery, Izmir/TURKEY
}

\begin{abstract}
Introduction and Objectives: We aimed at evaluating retrospectively effects of surgery on the clinical symptoms and signs and imaging parameters in the patients with Chiari's malformation undergoing surgical treatment.

Materials and Methods: Medical charts and radiological images of the patients with Chiari's Malformation type I who had surgical treatment between January 2008 and July 2014 were reviewed retrospectively. The patients were classified as those having good (in whom the symptoms disappeared or reduced), stabilized (with preoperative symptoms persisting without any progression), or poor (with preoperative symptoms progressing in the postoperative period) outcomes.
\end{abstract}

Findings: All patients underwent FMD, $\mathrm{Cl}$ laminectomy and duraplasty. Seventeen subjects underwent removal of arachnoid adhesions, 10 subjects underwent opening of the fourth ventricle, and one subject underwent subpial resection. Of the patients, 28 were female and 11 were male with ratio of females to males being 25:1. The youngest patient was 5 years old and the eldest one was 51 years old, and mean age of the patients was $3231 \pm 3131$ years. The subjects were divided in two groups based on presence or absence of associated syringomyelia: those with syringamyelia (Group 1, $\mathrm{n}=15$ ) and those without syringomyelia (Group 2, $\mathrm{n}=24$ ). Postoperatively, in the Group 1 (SM 1- CM) 10 (66.7\%) patients had good, $3(20 \%)$ had stabilized and $2(133 \%)$ patients had poor surgical outcomes. In the Group 2, 23 (918\%) subjects had good and $1(4.2 \%)$ subject had stabilized outcomes. For the Group 2, rate of recovery was higher than in the Group 1 (918\% and 66.7\%, respectively; Pearson's chi-square test, $\mathrm{P}=0.014)$. Rate of recovery in 21 subjects with degree of tonsillar herniation being more than $11 \mathrm{~mm}(95.2 \%)$ was statistically significantly higher than 18 subjects with degree of tonsillar herniation being less than $11 \mathrm{~mm}$ (72.2\%) (Pearson's chi-square test, $\mathrm{P}=0.047$ ).

Results: FMD is a safe and efficient surgical method for the Chiari malformations with or without associated syringomyelia. The subjects without associated syringomyelia benefited more from the surgery. Complications related to CSF may be reduced using additional tissue glues. Studies with greater number of cases should be conducted on the effect of degree of tonsillar herniation on surgical outcomes.

Keywords: Chiari's malformation, syringomyelia, decompression foramen magnum, duraplasty.

\section{Introduction}

Chiari Malformations are congenital anomalies which happen with the heterograde change in place of posterior fossa structures from foramen magnum through the cervical canal. The physiopathology of Chiari -I Malformation and the accompanying anomalies has always been an important issue. The natural history of complex disease has not been identified yet (1).

Chiari Malformations may be difficult to diagnose since they mostly have atypical and bizarre symptoms. A careful clinical evaluation is crucial for a proper diagnose and treatment. 
A consensus has not been reached about the treatment of Chiari Malformations alone or together with Syringomyelia. Even though Foramen Magnum decompression (FMD) is accepted widely for Chiari-I Malformation, there is no consensus on how the operation should be performed (2).

In this study we aimed to find the impact of surgery on clinic symptoms and findings, screening parameters and the relation between clinical results and surgical results -in a retrospective manner- on Chiari patients receiving surgical treatment.

\section{Material and Method}

The file information and radiological screenings of Chiari Malformation (CM) Type- I Patients who received surgical treatment in İzmir Katip Çelebi University Atatürk Education and Research Hospital Neurosurgery Clinic between January 2008 and July 2014 have been studied in a retrospective manner. This study serves to find the impact of surgery on clinic symptoms and findings, screening parameters and the relation between clinical results and surgical results.

The retrospective analyze of patient data and screening studies was conducted by the permission of İzmir Katip Çelebi University Non-Invasive Ethical Committee.

28 of a $39 \mathrm{CM} 1$ patients who took part in this study were women $(71,8 \%)$ and 11 were men $(28,2 \%)$. The ratio of women to men was $2,5: 1$. The youngest patient was 5 and the oldest patient was 51 years old and the average age of the patients was $32,31 \pm 35,31$. Seven of the patients were in pediatric age group.

All patients received preoperative cranial and craniocervical area MRI. Cerebrospinal fluid flow MRI was conducted in suspicious cases in order to determine whether there was a cerebrospinal flow obstruction on foramen magnum level. MRI Screenings were evaluated in terms of tonsilar herniation, syringomyelia and syringobulbia. The patients were divided into two groups radiologically according to the MRI Screenings: Patients with syringomyelia (group 1, 15 cases $(38,5 \%)$ ) and patients without syringomyelia (group 2,24 cases $(61,5 \%))$.

Due to concomitant bone anatomy, in some patients were CAT scanned and plane x-rayed. Concomitant anomalies were atlas assimilation in two cases, platybasia in three cases, bacillar impression and platybasia in one case, occipitalization in one case and scoliosis in one case.

Pre operation tonsilar herniation levels of the patients were measured and evaluated. Tonsilar herniation levels were between $5,8 \mathrm{~mm}$ and $29 \mathrm{~mm}$ and on average $12,7 \mathrm{~mm}$ long. Tonsilar herniation levels in all patients were longer than $5 \mathrm{~mm}$. Patients were categorized in three groups according to their herniation levels: Type $1(5-10 \mathrm{~mm}) 14$ cases $(35,9 \%)$, Type $2(10-20 \mathrm{~mm}) 22$ cases $(56,4 \%)$, Type 3 (more than $20 \mathrm{~mm})$ 4 cases $(7,7 \%)$.

Symptoms and findings were divided into six groups: Headache and/or neck pain, cranial nerve dysfunction, motor disorder, sensory disorder, gait disorder and sphincter dysfunction.

The symptoms of the patients lasted 30 months on average and varied between a minimum of 2 months and a maximum of 10 years. In general the course of symptoms was slow and progressive. Type 1 patients were having dominant central cort symptoms while group 2 patients were having brain stem compression findings and symptoms. The most common reference finding in patients with syringomyelia was sensory disorder (12 cases, $80 \%)$ and it was followed by headache and/or neck pain (10 cases, 66,6\%), motor disorder ( 8 cases, $53,3 \%$ ), gait disorder (4 cases, 26,6\%), cranial nerve dysfunction ( 2 cases, 13,3\%) and sphincter dysfunction ( 2 cases, $13,3 \%)$ respectively.

The most common reference finding in patients without syringomyelia (group 2) was headache and/or neck pain (22 cases, $83,3 \%$ ) and it was followed by sensory disorder ( 8 cases, 33,3\%), cranial nerve dysfunction (6 cases, 25\%), gait disorder (6 cases, $25 \%$ ), motor disorder (5 cases, 20,8\%) and sphincter dysfunction (1 case, $4,2 \%$ ) respectively.

\section{Surgical Technique}

All patients were operated by microsurgery technique using general anesthesia. The surgical operation was performed by changing the head and the neck from prom position to flexion position. 
Bone decompression is formed by a $3-4 \mathrm{~cm}$ diameter craniectomy which includes foreman magnum and $\mathrm{C} 1$ lamynectomy. After that, dura was opened in a y-shape and in order to prevent subarachnoid space from contacting with blood arachnoid was kept intact. After opening the dura, it was decided to leave arachnoid intact in patients with syringomyelia or patients without evident arachnoid pathology. In all other cases, under the operation microscope, arachnoid was incised starting from the inferior cerebellar tonsilles and was resected in order to let tonsilles separate from each other for foramen magendi inspection. Foreman magendi was inspected in ten cases by coagulating cerebellar tonsilles on ends .After that, duraplasty was enlarged by using autologous occipital fascia. In 23 cases tissue glue was used after duraplasty. Finally, the contusion was closed by suturing the muscular layer tightly.

After every operation, each patient's course, headaches or secondary incision aches, three days postop vomits. CSF leaks, fever, and contusions were carefully examined and noted. All patients were invited for check up and their neurological healing was noted. The patients were asked a three-optioned question in order to assess their recovery postop: well (symptoms have regressed completely or remounted a bit), stabilized (without progression preoperative symptoms continue) or bad (there is progress in preoperative symptoms). After that, the patients were classified as well group, who benefitted from the operation, stabilized and bad group were classified together who did not benefit from the operation.

Just after the operation each patient was cranial and upper cervical CAT scanned. Each patient, after they were discharged from the hospital suggested check up. It's understood from the ambulatory care notes that the cases with syringomyelia had their check-ups done more often. The length of follow up was between 3 months and 6 years and the average length of follow up was 2,6 years.

In both groups, the data about the length of the symptoms, the healing, the radiological healing with the range of sirinks, the complication range and reoccurrence incidence were collected and analyzed. The statistical analyze of the collected data were made via SPSS 15.0 for Windows. In comparing categorical data between groups, chi square test and independent sample t test were used. P>0,05 threshold was excepted as statistically significant.

\section{Findings}

In preoperative MRI screenings in 39 cases, tonsilar herniation (100\%) in 15 cases syringomyelia $(38,4 \%)$, in 39 cases obliterated cisterna magna $(100 \%)$ and in 20 cases, peg-like tonsilar were seen. Tonsilar herniation was longer than $5 \mathrm{~mm}$ in all patients,in 14 cases $(35,9 \%) 5-10 \mathrm{~mm}$ in 22 cases $(56,4 \%)$ between $10-20 \mathrm{~mm}$ and in 3 cases $(7,7 \%)$ it was longer than $20 \mathrm{~mm}$. Following FMD and C1 laminectomy, after dura was opened, in 17 cases $(43,5 \%)$ arachnoid dissection was performed, in order to get rid of the arachnoid adherences, in 10 cases $(25,6)$ the $4^{\text {th }}$ ventricle was opened and seen and in 1 case $(2,5 \%)$ tonsilar inferior end suppial resection was performed. In 12 of 17 cases where arachnoid adherence was detected, there was also syringomyelia. The other 5 patients were in group 2 where syringomyelia was not seen. In the meantime both arachnoid opening and $4^{\text {th }}$ ventricle anastomosis did not affect post surgery symptomatic results. In MRI screenings, 15 cases showed syringomyelia where 7 of these syringomyelia was limited in cervical region $(46,6 \%)$, in 8 cases $(53,4)$ cervicothoracal syringomyelia was seen. In 1 case $(2,56 \%)$, syringobulbia was detected. None of the patients had syringomelia which reached conus medullaris. When preop and postop MRIs of 11 patients whith concomitant syringomyelia were examined after decompression, it was seen that 9 of them $(81,8 \%)$ had reduction in syrinx size and 2 cases had no change in syrinx size (figure 9) . 10 of the patients were women, 5 were man in the cases where syringomyelia was seen. In CM cases, syringomyelia was seen in $35,7 \%$ of women and $45,4 \%$ in men. Preop and postop CSF flow MRIs were taken of 2 cases in group 1 and 4 cases in group 2. In all these cases CSF flow in foramen magnum posterior was higher in postop MRI compared to preop MRIs (figure 10). In all 15 cases where MRIs were taken, there was CSF flow in posterior on foramen magnum level. After evaluating postop MRIs, each 28 case had a new cisterna magna formation.

Patients were categorized as well (symptoms have regressed completely or remounted a bit), stabilized (without progression preoperative symptoms continue) or bad (there is progress in preoperative symptoms). Among all patients, 32 cases $(84,6 \%)$ were well, 4 cases $(10,3 \%)$ were stabilized and 2 cases $(5,1 \%)$ were bad. 2 cases got worse after decompression. This can be counted as a 5,1\% surgical morbidity rate. In group 1 (SM+CM) 10 cases $(66,7 \%)$ were well, 3 cases $(20 \%)$ were stable and 2 cases $(13,3 \%)$ were bad in terms 
of postop surgical results. On the other hand in group 2 (CM) 23cases $(95,8 \%)$ were well and 1 case was stable. In other words, findings did not change postop. When the healing ratio of the cases were compared after decompression, the healing ratio in group 2 was significantly higher than patients in group 1 (respectively $95,8 \%$ and $66,7 \%$; Pearson chi-square test $\mathrm{P}=0,014$ ).

The average age of the healing patients (33 cases) was $32,88 \pm 13,34$, non-healing patients (6 cases) was $35,17 \pm 16,03$. However, this difference was not statistically significant (independent sample t test $P=0,710$ ). There was no statistically significant interaction between gender and surgical results.

1 patient with ingravescent findings was given craniocervical intersection and CSF flow MRI. MRIs showed that this patient had CSF flow in foramen magnum posterior and new cisterna magna formation. According to MRI results, the symptoms of the case were thought to be related to cervical orifice and the patient was given laminoplasty operation due to cervical orifice. Patient was stabilized after the second operation. The other patient with ingravescent findings was exitus in $4^{\text {th }}$ day postop due to sudden respiratory insufficiency and constituted a 2,5\% mortality rate. The average hospital stay of the patients was 3,8 days.

There was no significant difference between groups when the effect of symptoms in preop period on surgical results was considered. Symptoms continued for 32,2 months $\pm 37,5$ in the healing group, 52,5 $\pm 21,5$ in the non-healing group. There was no statistically significant difference $(\mathrm{P}>0,05)$.

In the healing group (33 cases) tonsilar herniation was $13,7 \pm 57,5 \mathrm{~mm}$ and in the non-healing group (6 cases) $10,1 \pm 25,6 \mathrm{~mm}$. Although the difference was not statistically significant $(\mathrm{P}=0,163)$, it was still remarkable. In 18 patients with less than $11 \mathrm{~mm}$ tonsilar herniation, the healing rate was low $(72,2 \%), 21$ patients with more than $11 \mathrm{~mm}$ tonsilar herniation, the healing rate was higher $(95,2 \%)$. There was a statistically significant difference between groups (Pearson chi-square test $\mathrm{P}=0,047$ ). In future research, the effect of tonsilar herniation level on post surgical healing process must be examined.

There was $90 \%$ healing in headache in patients with headache- neck pain $(27 / 30), 66,7 \%$ healing in patients without headache- neck pain (6/9). This finding is remarkable although it is statistically insignificant (Pearson chi-square test $\mathrm{P}=0,089$ ).

The healing ratio in patients with sensory disorder was less $(15 / 20,75 \%)$ than patients without sensory disorder $(18 / 19,94,7 \%)$. This finding is remarkable although it is statistically insignificant (Pearson chisquare test $\mathrm{P}=0,088)$.

There was no significant relation found between motor disorder, cranial nerve dysfunction, sphincter dysfunction, gait dysfunction and surgical result.

There was no significant relation between syringomyelia resorption and surgical result. One patient out of two, who didn't have syringomyelia resorption, healed and one remained in the non-healing group. 5 patients $(56,4 \%)$ out of 9 patients, who had resorption healed, $4(44,6 \%)$ remained sick. There was no statistically significant difference (Fisher exact test $\mathrm{P}=1$ ).

Postoperative complications were meningitis in 3 cases $(7,6 \%)$, CSF flow in 4 cases $(10,2 \%)$, wound site collection in 3 cases $(7,6 \%)$, hydrocephaly in 2 cases $(5,1 \%)$ and superficial wound infection in 1 case $(2,5 \%)$. The 3 meningitis cases were treated during the hospital stay, using antibiotics. One of 3 cases where superficial wound infection was seen had progressed in short term and regressed after 3 day drainer LP. In the other 2 cases wound site collection occurred 1 month preop and these patients were interned and treated. In 2 cases the wound site collection regressed after lumbar drainage. All of the 4 cases with CSF flow occurred in the early period and were treated during the hospital stay with drainer LP. The patients with wound site infection were treated by medical dressing. For the follow up of the cases with hydrocephaly there was no need for shunting. For all complications there was no need for re-operation in none of the cases. However, complications increased the length of the hospital stay and the risk of morbidity.

In 3 cases tissue glue (Tisseel fibrin glue) was used after duraplasty, CSF flow in one case and wound site collection in another case was seen as a complication. The group, in which tissue glue was used (23 cases) had less CSF complication ratio compared to the group in which tissue glue wasn't used (16 cases) (respectively, 8,7\% and 31,2\%; Pearson chi-square test $\mathrm{P}=0,071$ ). These findings are remarkable although 
they are not statistically significant. In future studies effect of tissue glue usage on CSF complications should be investigated.

\section{Discussion}

Chiari 1 malformation has variable clinical course and pathological findings. Variations in symptomatology make it hard to handle these patients properly without a classification system. In this study,the patients were classified as 2 groups according to their MRI groups: Cases with syringomyelia (Group 1, 15 cases), cases without syringomyelia (Group 2, 24 cases).

There is still no consensus on the most proper treatment for $\mathrm{CM}$ alone or together with syringomelia. Although, foramen magnum decompression is widely accepted for Chiari 1 Malformation, there is still no consensus on how to perform the operation. All of the past and contemporary surgical approaches contain a suboccipital craniectomy, although they may vary in size. Even though a lot of neurosurgeons recommend a large suboccipital craniecyomy with a wide lateral resection of foramen magnum reaching both occipital condyle (3), others adopt a more limited suboccipital craniectomy to minimize postop craniocervical instability and cerebellar herniation (3,4). Decompression size was limited to a $3-4 \mathrm{~cm}$ Foramen magnum decompression. In all cases in this research, this procedure included dissecting medial part of atlas. Nowadays there has been a consensus on the level od dissected bone.

There is a serious debate on whether the approach should be intradural or extradural. All intradural approach advocates believe that duraplasty is very important for enabling a new cisterna magna formation and obtaining CSF flow between intracranial and spinal cavity $(19,20)$. In addition, it is believed that in operations where duraplasty is performed, the risk of postop complications such as hydrocephaly, aseptic meningitis, CSF leakage or pseudomeningocele is increased.

In patients with brain stem compression (group 2, 24 cases), simultaneous with extraction of atlas' posterior arcus, a foramen magnum, which consisted of a small suboccipital craniectomy, was performed. Except for 4 cases, arachnoid was left intact with a dura opening. In these 4 cases arachnoid dissection was performed, since arachnoid adherence was detected. In all cases autologous duraplasty was performed, in order to enable new cisterna magna formation and CSF flow in foramen magnum region. Cerebellar tonsils were under serious pressure, even after bone decompression and opening a dura released that pressure. Intraoperatively, reemergence of pulsations was a sign of cerebellar tonsils' relief. Adding duraplasty to bone decompression enabled relieving brain stem compression and CSF flow on foramen magnum level.

In all cases with syringomyelia (group 1, 15 cases), foramen magnum decompression and atlas' posterior arcus were extracted. In order to reveal $4^{\text {th }}$ ventricle and keep the orifice, arachnoid adherences were removed. For us, this surgical procedure is a necessary step to treat syringomelia. When there were no adhesions, a duraplasty was performed and procedure was ended. Except for 2 cases with no arachnoid adherence, in all cases arachnoid dissection was performed. When adhesions were detected, microscopical dissections were carefully performed and it was limited to opening of foramen magendi. In order to minimize vascular damage in posterior inferior cerebellar artery or brain stem damage and avoid postop arachnoiditis, an aggressive intra-arachnoid dissection was shunned. Only in one case syringosubarachnoid shunt application was performed. In none of the cases an obex plugging operation was performed. It is known that opening a shunt in syrinx and obex plugging is related to a high reccurence rate(3).

Arachnoid dissection is still controversial. Some of arachnoid adherences have an inhibiting potential for letting tonsils to a more normal position. Inspection of subarachnoid cavity, especially in cases with syringomelia which don't show serious levels of tonsilar herniation in screenings like the ones in İskandar,et al.'s study, arachnoid exploration is important(4). Reduction of cerebellar tonsils enables $4^{\text {th }}$ ventricle orifice and continuity of CSF flow from the $4^{\text {th }}$ ventricle. As a result, reduction of tonsils widens subtonsilar and retrotonsilar cisterns, which leads to syrinx resolution and reduces the pressure on superior cervical roots. Although some other researchers exprressed their concern in their studies, we didn't come across any complications regarding scar tissue formation by opening arachnoid or cerebellar tonsils reduction (4). Milhorat and Bolognese adapted their operation stages to intraoperative CSF flow measurements by 
ultrasound and in light of these criteria, found it necessary to perform arachnoid dissection in most of the cases (5). However there was no information about postop findings in both studies.

In a study by Junpeng et al., 76 patients received FMD and duraplasty: 61 cases were healed (80,26\%), 12 cases were stable (15,79\%) and 3 cases were worsened (3.95\%) (58). In 2012 Lee et al. performed FMD to 25 patients with Chiari 1 Malformation. 20 cases $(80 \%)$ were healed, 4 cases $(16 \%)$ were stable and 1 case (4\%) was worsened. In our study, out of $39 \mathrm{CM}$ patients, 33 cases $(84,6 \%)$ reported that they healed postop, 4 cases $(10,3 \%)$ were stable and 2 cases $(5,1 \%)$ worsened $(6)$.

In a study by El-Ghandour et al. out of 32 cases with Chiari 1 malformation plus syringomyelia were treated with FMD; 14 cases $(43,8 \%)$ healed, 18 cases $(56,3 \%)$ were stable. In group without syringomelia 10 cases $(71,4 \%)$ were stable and 4 cases $(28,6 \%)$ healed (60). In a study, Junpeng et.al divided their patients into two groups: Chiari 1 malformation patients with and without syringomyelia. In group 1 with syringomyelia out of 56 cases, 43 cases $(76,8 \%)$ healed, 10 cases $(17,8 \%)$ were stable and 3 cases $(5,4 \%)$ worsened. In group 2 without syringomyelia 18 cases $(90 \%)$ healed and 2 cases $(10 \%)$ were stable (58). In our study in group 1 patients $(\mathrm{SM}+\mathrm{CM}), 10$ cases $(66,7 \%)$ had good, 3 cases $(20 \%)$ had stable and 2 cases $(13,3 \%)$ had bad postop surgical results. On the other hand, in group $2(\mathrm{CM}) 23$ cases $(95,8 \%)$ had good and 1 case $(7,8)$ had stable postop findings. When the rate of healing after decompression between two groups was compared, cases in group 2 had significantly higher healing rate than cases in group 1 (respectively, 95,8\% and 66,7\%; Pearson chi-square test $\mathrm{P}=0,014$ ).

Among postop complications, in 3 cases $(7,6 \%)$ there was aseptic meningitis, in 4 cases $(10,2 \%)$ CSF flow, in 3 cases $(7,6 \%)$, wound collection, in 2 cases $(5,1 \%)$ hydrocephaly, and in 1 case $(2,5 \%)$ flesh wound infection. 3 cases with aseptic meningitis scenario were treated during the hospital stay. 1 of 3 cases with wound infection was short-termed and regressed after 3 day drainer LP. In two other cases, wound collection was developed 1 month after operation and they were treated by interning them again. 2 cases' wound collection was regressed after lumbar drainage. All of 4 CSF flow leakage cases were developed in early periods and they were treated with drainer LP's during their stay at hospital. A case with superficial wound infection was treated by dressings. Finally, there was no need to shunt application in cases with hydrocephaly.

In literature there is limited information about surgical morbidity. Hoffmann and Souweidane reported that the surgical morbidity rate was $2,5 \%$ for patients who were treated by decompression and duraplasty, but without opening arachnoid (50). Ellenbogen et al. informed that in 65 patients who received arachnoid dissection, duraplasty and decompression, the surgical morbidity rate was a high 6,5\% (9). In another study, where 157 adult Chiari related syringomyelia patients were operated by intra-arachnoid approach; 29 cases $(18,5 \%)$ encountered postop complications and these complications consisted of neurological deficits $(5,7 \%)$, meningitis $(3,8 \%)$, isolated fever without infection $(3,8 \%)$, cervical and extremity pain $(3,2 \%)$, occipital pseudomeningocele (1,3\%) and CSF leakage (0,6\%) (44). In Zhang et al.'s study out of 69 patients who received wide spectrum FMD and duraplasty reported complications were; wound bleeding in 3 cases $(4,3 \%)$, wound infection in 1 case $(1,4 \%)$, aseptic meningitis in 4 cases $(5,7 \%)$, CSF leakage in 8 cases $(11,5 \%)$, hydrocephaly in 2 cases $(2,8 \%)$, cerebellar ptosis in 5 cases $(7,2 \%)$ and occipitocervical instability in 5 cases $(5,7 \%)$.

In our study, most common complication was CSF syrinx in 10,2\% of the cases. Literature indicates that usage of tissue glue doesn't reduce this rate (10). However, in our study, when the group (23 cases) where tissue glue is used is compared to the group (16 cases) where tissue glue isn't used, there was a lower rate of CSF related complications (respectively, 8,7\% and 31,2\%; Pearson chi-square test $\mathrm{P}=0,071$ ). Although this difference wasn't statistically significant, it was remarkable. Further research about the effects of tissue glue on CSF complications-using bigger series- is required.

In this series, hydrocephaly, which formed $5,1 \%$ of cases after decompression, is an important postop compliaction which should be investigated. The question whether postop ventricular dilatation requires surgical treatment or not, should be answered depending on clinical course. Hydrocephaly can recover spontaneously (11). These 2 cases' postop clinical and radiological tracking showed that, there was no need for shunt. 
It was mentioned that central canal syrinxes cause unrepairable damage on spinal nucleuses and traktuses (12) and this has explained why some patients couldn't recover, although syrinxes were gone. There was no significant relation between syringomelia resorption and surgical results. 1 of 2 patients with no syringomelia resorption was healed and other didn't heal. Out of 9 cases with resorption 5 cases $(56,4 \%)$ were healed and 4 cases $(44,6 \%)$ didn't heal. There was no statistically significant difference (Fisher exact test $\mathrm{P}=1$ ).

In group $1(\mathrm{SM}+\mathrm{CM}) 10$ cases $(66,7 \%)$ had good, 3 cases $(20 \%)$ had stable and 2 cases $(13,3 \%)$ had bad postop surgical results. However, partial healing or stabilisation of syrinx symptoms can be counted as a successful result in these patients, due to progressive nature of syringomyelia. In group 1, when preop and postop MRIs of 11 cases were analyzed after decompression; 9 cases $(81,8 \%)$ had reduction in syrinx size, 2 cases $(18,2 \%)$ had no change in syrinx size. In another study, where a large suboccipital craniectomy and intra-arachnoid approach was used, $75,6 \%$ of cases had reduction in syrinx size, $21,2 \%$ of cases had no change and 3,2\% of cases had larger one (13).

When the effect of symptoms' continuance in preoperative stage on surgical results was compared between two groups, no difference was found. In healing group, symptoms' continuance was $32,2 \pm 37,5$ months, in non-healing group it was $52,5 \pm 21,5$ months. Statistically there was no significant difference $(p>0,05)$. However, when the continuance of preoperative symptoms and surgical results is scrutinized, there was a significant relation between a good surgical result and shortness of symptoms, especially in CM cases with syringomyelia.

In the long term follow up of CM 1 patients, the data and the reoccurrence incidence after surgical decompression are only a few. In a long term study (88 months average) including 157 adult patients with syringomyelia related to Chiari, 6 cases $(3,8 \%)$ were operated again 38 months average after the first operation. In 2 cases out of the 6 failure was engaged to partial decompression at the beginning (14).

In our study, there was no reoccurrence in $39 \mathrm{CM}$ cases with the average 2,6 years observation period $(0 \%)$. However, in 1 case which got worse, cranio cervical junction and CSF flow MRI was made. Case 2 stabilized in postop follow up. CM 1 creates vulnerability to degenerative disc disease because of the restricted movement of the superior cervical spine (15). Patients with syringomyelia have spinal cord atrophy despite the regression of syrinx. Even middle level degenerative changes of cervical spine may cause serious neurological deficits (16). This may seem neglected because screening studies mostly makes one think there is no space for cord with atrophy in cervical stenosis area.

Tonsilar herniation more than $5 \mathrm{~mm}$ is considered as pathologic in adults $(17,18)$. However, the radiologic criteria are not absolute for tonsilar herniation degree and should be considered as clinicopathologic. In our study, 18 patients with tonsilar herniation less than $11 \mathrm{~mm}$, had low healing rate $(72,2 \%)$, while 21 patients with tonsilar herniation more than $11 \mathrm{~mm}$ had high healing rate $(95,2 \%)$. There was a statistically significant difference between two groups (Pearson chi-square $\mathrm{P}=0,047$ ). Studies should be made on the effect of tonsilar herniation degree on healing preop in bigger series.

In this syudy, MRI screening was very helpful for diagnose and finding out whether there was syrinx or not and identifying the reason of the symptoms with the localisation of syrinx. 15 cases out of 39 CM1 cases $(38,5 \%)$ had syringomalia. The data we gained shows that there is no corellation between tonsilar herniation and syringomyelia formation. Other writers stated that statically there is no certain corellation between tonsilar dent, the severity of the symptoms and syringomyelia cavity (19).

CM 1 malformations can be hard to diagnose since they show different symptoms. Syndrome has a clinical variability which makes it difficult to diagnose or may lead to misdiagnose. The symptoms and findings incidence of our patient group (table 2) shows only a slight difference from the other series reported $(20,21,22)$. The most common finding in Group 1 was sensorial disorder and headache followed that. The most common finding was headache in Group 2 and sensorial disorder followed that.

The symptomps of Chiari malformations are related to age: while apneic seizures, cyanosis seizures, swallowing difficulties and brain stem compression are dominant in infantile period, scoliosis is the most common symptom in the later childhood period. Typical clinical findings are headache, gait ataxia, sensory 
disorders and motor disorders are not commonly seen in children. They are dominantly seen in adults $(23,24)$. Headache showed the biggest postop healing rate in early follow up (25).

In this study, healing rates observed were 90\% (27/30) in cases with head/ neck pain and 66,7\% (6/9) in cases without head/neck pain. Although it is not statistically significant, it is worth paying attention (Pearson chi-square test $\mathrm{P}=0,089$ ).

\section{Results}

Foramen magnum decompression and duraplasty is a safe and effective surgical method for Chiari 1 malformations with or eithout syringomyelia. Decompressive surgery reduced the brainstem pressure dramatically and healed or stabilized the symptomps related to syringomyelia. Cases with Chiari 1 malformations without syringomyelia benefitted more from the surgical treatment. However, since syringomyelia is a progressive disease, in those cases the stabilization of these symptoms is seen as a surgical success.

After adding duraplasty to Foramen Magnum decompression, cisterna manga formation was observed in all patients. Duraplasty may cause resolution in syringomYelia by increasing the CSF transmission in Foramen Magnum posterior; but minor complication rates in duraplasty are higher. The most common complications related to CSF, can be reduced by using tissue adhesives like we did in our study. However, studies should be made about the impact of tissue adhesive on CSF complications in bigger series.

In our study, cases with more than $11 \mathrm{~mm}$ tonsil herniation degrees and preop head and neck pain benefitted from the treatment more. Doing studies on bigger series, an algorithm can be developped for Chiari 1 malformation patients.

\section{References}

[1.] Schijman E, Steinbok P. International survey on the management of Chiari I malformation and syringomyelia. Childs Nerv Syst. 2004; 20 (5): 341-348.

[2.] Aghakhani N, Parker F, David P, Morar S, Lacroix C, Benoudiba F, Tadie M Long-term followup of Chiari-related syringomyelia in adults: analysis of 157 surgically treated cases. Neurosurgery 2009; 64: 308-315.

[3.] Perrini P, Benedetto N, Tenenbaum R, Di Lorenzo N : Extraarachnoidal cranio-cervical decompression for syringomyelia associated with Chiari I malformation in adults: technique assessment. Acta Neurochir (Wien) 2007; 149: 1015-1023.

[4.] Di Lorenzo N, Palma L, Palatinsky E, Fortuna A "Conservative" cranio-cervical decompression in the treatment of syringomyelia-Chiari I complex. A prospective study of 20 adult cases. Spine 1995; 20: 2479-2483.

[5.] Botelho RV, Bittencourt LR, Rotta J M, Tufik S: The effects of posterior fossa decompressive surgery in adult patients with Chiari malformation and sleep apnea. J Neurosurg 2009. [Epubahead of print]

[6.] Bindal AK, Dunsker SB, Tew JM Jr Chiari I malformation: classification and management. Neurosurgery 1995; 37: 1069-1074.

[7.] Klekamp J, Batzdorf U, Samii M, Bothe HW The surgical treatment of Chiari I malformation. Acta Neurochir (Wien) 1996; 138: 788-801.

[8.] Iskandar BJ, Hedlund GL, Grabb PA, Oakes WJ: The resolution of syringohydromyelia without hindbrain herniation after posterior fossa decompression. J Neurosurg 1998; 89: 212-216.

[9.] Heiss JD, Suffredini G, Smith R, DeVroom HL, Patronas NJ, Butman JA, et al: Pathophysiology of persistent syringomyelia after decompressive craniocervical surgery. Clinical article. J Neurosurg Spine 2010; 13: 729-742.

[10.] Milhorat TH, Bolognese PA. Tailored operative technique for Chiari type I malformation using intraoperative color Doppler ultrasonography. Neurosurgery. 2003; 53 (4): 899-905; discussion 905-906. 
[11.] Lee HS, Lee SH, Kim ES, Lee JI, Shin HJ, Eoh W. Surgical result of arachnoid-preserving posterior fossa decompression for Chiari 1 malformation with associated syringomyelia. Journal of Clinical Neuroscience 2012 Apr;19(4):557-60.

[12.] El-Ghandour, Nasser M. Long term outcome of surcigal management of adult Chiari 1 malformation. Neurosurg Rev. 2012 Oct;35(4):537-46.

[13.] Junpeng MA, Chao YOU, Haifeng CHEN, Siqing HUANG, Chengcheng IEONG. Cerebellar tonsillectomy with suboccipital decompression and duraplasty by small incision for Chiari 1 Malformation. Turkish Neurosurgery 2012 ;22(3):274-9.

[14.] Hoffman CE, Souweidane MM. Cerebrospinal fluid-related complications with autologous duraplasty and arachnoid sparing in type I Chiari malformation. Neurosurgery. 2008; 62 (3 suppl 1): 156-160; discussion 160-161.

[15.] Ellenbogen RG, Armonda RA, Shaw DW, Winn HR. Toward a rational treatment of Chiari I malformation and syringomyelia. Neurosurg Focus. 2000; 8 (3): E6.

[16.] Zhang Y, Zhang N, Qui H, Zhou J, Li P, Ren M. An efficacy analysis of posterior fossa decompression tecniques in the treatment of Chiari malformation with associated syringomyelia. Journal of Clinical Neuroscience. 2011 Oct;18(10):1346-9.

[17.] Parker SR, Harris P, Cummings TJ, George T, Fuchs H, Grant G. Complications following decompression of Chiari malformation Type I in children: dural graft or sealant $\mathbf{J}$ Neurosurg Pediatr. 2011; 8 (2): 177-183.

[18.] Marshman LA, Benjamin JC, Chawda SJ, David KM. Acute obstructive hydrocephalus associated with infratentorial subdural hygromas complicating Chiari malformation Type I decompression. Report of two cases and literatürereview. J Neurosurg. 2005; 103 (4): 752-755.

[19.] Milhorat TH, Capocelli AL Jr, Anzil AP, Kotzen RM, Milhorat RH: Pathological basis of spinal cord cavitation in syringomyelia: analysis of 105 autopsy cases. J Neurosurg 1995; 82: 802-812.

[20.] Takeuchi K, Yokoyama T, Ito J, Wada K, Itabashi T, Toh S. Tonsillar herniation and the cervical spine: a morphometric study of 172 patients. J Orthop Sci. 2007; 12 (1): 55-60.

[21.] Klekamp J. Surgical treatment of Chiari I malformation analysis of intraoperative findings, complications, and outcome for 371 foramen magnum decompressions. Neurosurgery. 2012; 71: 365-380.

[22.] Aboulezz AO, Sartor K, Geyer CA, Gado MH. Position of cerebellar tonsils in the normal population and in patients with Chiari malformation: a quantitative approach with MR imaging. $\mathrm{J}$ Comput Assist Tomogr. 1985; 9 (6): 1033-1036.

[23.] Oakes WJ, Tubbs RS: Chiari malformations. Winn HR (ed) Youmans neurological surgery, ucuncu bask1, Philadelphia: Elsevier 2004: 3347-3361.

[24.] Klekamp J: The pathophysiology of syringomyelia - historical overview and current concept. Acta Neurochir (Wien) 2002; 144 (7): 649-664.

[25.] Williams B: Cerebrospinal fluid pressure-gradients in spina bifida cystica, with special reference to the Arnold-Chiari malformations and aqueductal stenosis. 